\title{
Are the physical structures of health units and the primary health care teams adequate to receive and provide care for the elderly?
}

\begin{abstract}
This study assessed the adequacy of physical structures and the signage in health units in a capital city of southern Brazil, as well as the adequacy of health teams regarding the needs of the elderly. In this cross-sectional study, checklists were applied for auditing the access and the signage in primary health care centers, and inquiries were made on the characteristics of health teams regarding the adequacy for the needs of the elderly. The results showed that most units were inadequate for both structure and signage issues. When comparing the Family Health Units (FHUs) and Basic Health Units (BHUs), the FHUs showed better results for the physical structure, signage, professional training in health care for the elderly, presence of group activities, and telephone scheduling. There were differences between the recommendations of the World health Organization regarding the adequacy of physical structures and signage and the actual situation of health units. These findings indicate important limitations for the accessibility of elderly users of said health care, representing a major barrier in the search for care and the assurance of principles of primary health care. The better results of the FHUs indicate this health care model as most suited to the care of the elderly population.
\end{abstract}

Keywords: health care accessibility, elderly care, accessibility structures, comprehensive health care
Volume 8 Issue 6 - 2017

\section{Roberto Luz Pretto, Matheus Neves, Otavio Pereira Davila, Aline Blaya Martins, Fernando Neves Hugo}

Department of Dentistry, Federal University of Rio Grande do Sul, Brazil

Correspondence: Matheus Neves, Department of Dentistry, School of Dentistry, Federal University of Rio Grande do Sul, Porto Alegre, Rio Grande do Sul, Brazil, Email matineves@gmail.com

Received: November 03, 2017 | Published: November 15, 2017

\section{Introduction}

The access to health services is the first contact in the provision of health care. It has long been known that the elderly, in particular, represent a portion of the population that faces barriers for accessing health units, due to the lack of accessibility devices that consider their physical and mobility challenges, as well as the lack of adequacy of physical structures of health units to allow offering a quality service directed to the needs of these users. ${ }^{1,2}$ The Brazilian population has been going through an ageing process due to the following aspects:

1. Low birth rates.

2. Behavioral changes that result in better quality of life.

3. Epidemiological transition from infectious and contagious diseases to chronic and degenerative diseases. ${ }^{3}$

The increased longevity of the Brazilian population causes the elderly to naturally present a higher prevalence of physical limitations, which may result in the need for support from other people to perform daily activities, as well as devices such as wheelchairs and crutches. ${ }^{4}$ Consequently, the accessibility conditions are associated with the high prevalence of falls among elderly people. ${ }^{5}$ According to Ribeiro et al., ${ }^{6}$ falls are frequent in this portion of the population and their consequences affect directly the quality of life of these individuals. The proper adequacy of the physical environments and health promotion strategies should be established to provide an active ageing that is independent and healthy. Evidence shows that such strategy is worth for residences as well as for the health care network accessed by the elderly. ${ }^{2-5}$ Such factors have been observed and highlighted by public policies focusing on the health care of the elderly, such as the Active Ageing and the Toward Primary Health Care-Age-friendly, in the global scope, and the Elderly Health Policy, the Statute of the Elderly, the Pact for Life, and the National Health Policy for the Elderly, in the Brazilian scope. In the primary health care scope, the World Health Organization (WHO) launched the "Age-friendly Primary Health Care Centres Toolkit". This manual acknowledges the essential role of primary health care teams as care providers to the elderly and establishes some parameters to qualify this service. This manual includes protocols for preventing and handling more prevalent diseases, as well as checklists that seek to indicate devices and attitudes required for the health units to be completely adapted to the needs of the elderly population, regardless of the degree of physical, motor, or emotional impairment of the individual. ${ }^{7}$ Considering that such document is the reference for Brazilian application protocols of primary care to the elderly, ${ }^{8}$ it is believed that the health units should be adequate to the needs of this population by offering better accessibility to the elderly. Thus, aiming to establish the adequacy of health units for accessibility and the adequacy of the health team for elderly care, this study proposes to assess the current conditions of some health units in the city of Porto Alegre, Rio Grande do Sul, Brazil. It also seeks to describe and compare the presence of practices related to the comprehensive and integrated care, such as priority access, home visits, oral health care, access of wheelchair users to the dental office, and group activities for the elderly, in Basic Health Units and Family Health Units.

\section{Method}

It is a cross-sectional study to assess the adequacy of physical structures, signage of areas and work processes of the health teams from the Basic Health Units and the Family Health Units in a capital city of southern Brazil. 


\section{The setting}

All primary health care units located in two health districts of a capital city of Brazil were assessed. According to data from the municipal management, in 2011 there were 19 primary health care units in this coverage area - 8 Basic Health Units (BHUs) and 11 Family Health Units (FHUs). Moreover, this region includes a surrounding population of 200,000 inhabitants and the elderly population consists of approximately 13,000 individuals in this area, according to data from the last census. ${ }^{9}$ It is worth noting that a Family Health Unit includes a family health team consisting of professional physicians, nurses, technicians, and community health agents, and it may or may not include an oral health team, performing the basic care model in Brazil also known as Family Health Strategy. On the other hand, a Basic Health Unit may include several health professionals, not necessarily gathered in a family health team, performing a different work regime from the Family Health Strategy.

\section{Assessment measures}

The following instruments used were developed by the World Health Organization, ${ }^{7}$ based on the principles of universal design:

Registration form of the health unit: contained the name of the health center, the name of the coordinator, the time since either the health unit started running or the last renovation was performed, and date of auditing.

Checklist for auditing the access to primary/basic health centers: the instrument included 44 questions of mostly simple answers (yes/ no, or absolute width/height value), which are distributed as follows:

1. Accessibility to public transportation (three questions).

2. Entrance (four questions on staircases and access ramps, and five questions on the access to entrance doors and on wheelchairs and obstacles for people with limited mobility).

3. Parking (two questions).

4. Elevators (four questions about larger health centers higher than one floor),

5. Public Telephone (one question).

6. Access and safety inside the health units (nine questions on circulation and safety conditions against falls and potential accidents).

7. Bathrooms (six questions on access, safety, and comfort regarding the bathrooms),

8. Food location (three questions on the availability of food and water inside the health units or nearby).

9. Staircases (four questions directed to larger health centers higher than one floor).

10. Hallways (three questions).

Checklist for auditing the signage of Primary Health Centers: the instrument included 20 questions of mostly simple answers (yes/no, or absolute width/height value), which are distributed as follows:

Signage design (nine questions on the shape and disposition of indicative signs in the health units).
Signage location (seven questions).

Size of the letters in the signs (one question).

Team identification (three questions).

Additional questions: the following questions were integrated to the assessment of the health units - "Has any member of the team attended training/specialization courses on elderly health care? If yes, how many?" According to the distribution, the answers were ranked as 0 , 1 , or 2 or more; "Is there any type of easier access to elderly people? If yes, which one?" Considering that all the respondents who said "yes" referred to the telephone scheduling, the answers were classified as having or not such access device. The following questions received dichotomous "yes" or "no" answers - "Does the health unit offers any type of elderly group for its users?"; "Does the health team perform home visits to bedridden elderly people?"; "Is there a dental office in the running health unit? If yes, is it accessible to wheelchair users?"

\section{Training of evaluators}

The team was trained primarily through the reading of the manual "Age-Friendly Primary Health Care Centres Toolkit", proposed by the WHO in 2008.7 The instrument to be used in the checklist of units was analyzed, followed by a pilot study performed in the School of Dentistry of the Federal University of Rio Grande do Sul (UFRGS), Brazil. The measurements of height/length ratio of the ramps, presence and height of handrails, and width of doors and hallways were assessed at least three times to evaluate measurement agreements among the three examiners who formed the team in charge of data collection. Concomitantly to these measurements, the signage was also assessed and after the three members of the team reached a consensus, an evaluative attribution of such items was performed.

\section{Data analysis}

For data analysis, one point was attributed to each item from the list that was considered adequate. Next, the ranked items from each checklist were added to obtain a score. Lastly, a final score was attributed by adding the scores from all lists. As for classification, the health units with less than $50 \%$ of the items agreeing with the recommendations were considered "inadequate" for access and/or signage. The units with all items agreeing with the recommendations were considered "completely adequate". Those between 50 and 99\% were considered "partially adequate". The data collected were descriptively analyzed by measuring central and dispersion tendencies, and frequency analyses were performed. The statistical analysis was performed in the software SPSS 18.0.

\section{Results}

From a total of 19 health units assessed, 58\% were FHUs and $42 \%$ were BHUs, with average of 47 months since the inauguration or renovation. Most of the units were only one-floor high. Regarding the physical structures, most health units were partially adequate or inadequate. Such findings were repeated for signage. In a general score, the units were predominantly inadequate $(52.6 \%)$ (Table 1$)$. When comparing BHUs and FHUs regarding physical structures, proportionally, a higher number of BHUs was inadequate. The BHUs were superior only for the parameter "hallways" (Table 2). As for signage design, most health units $(73.7 \%)$ were partially inadequate, and most of the adequate units were FHUs. The parameter "signage 
location" was inadequate in most units. The "size of letters in signs" was inadequate in $100 \%$ of units (Table 3). Regarding the health professionals included in the teams, there was a majority of physicians, nurses, dentists, and nursing technicians. Almost all BHUs had only one health team, while most of the FHUs had two teams. When comparing both types of health care model, none of the BHUs had a community health agent, while most of the FHUs did. Proportionally, there were one or more professionals trained for managing the health of the elderly in Family Health Units, which was not true for traditional Basic Health Units. As for the presence of elderly groups, such practice was observed in a significant number of units among the ones assessed. Home visits to bedridden elderly people and the scheduling of appointments by phone were also practices directed to the needs of the elderly that were observed in essentially all health units (Table 4). Regarding the presence of a dental office, most units had one, but it was observed that in some of these health services, such resource was not accessible to wheelchair users (Table 4).

Table I Frequency distribution of the checklist parameters in a capital city in southern Brazil, 20I I

\begin{tabular}{lll}
\hline Characteristics of the Units & N (\%) \\
\hline Months since inauguration & & $46.58(47.13)$ \\
& 1 & $14(73.7)$ \\
Floors & 2 & $4(21)$ \\
& 3 & $1(5.3)$ \\
& BHU & $8(42.1)$
\end{tabular}

Primary health care mode FHU

Physical structures

\begin{tabular}{|c|c|c|}
\hline \multirow{2}{*}{ Transportation } & Inadequate & $12(63.2)$ \\
\hline & Partially adequate & $7(36.8)$ \\
\hline \multirow{2}{*}{ Entrance } & Inadequate & $10(52.6)$ \\
\hline & Partially adequate & $9(47.4)$ \\
\hline \multirow{2}{*}{ Parking } & Inadequate & I 6 (84.2) \\
\hline & Partially adequate & $3(15.8)$ \\
\hline Elevator & Inadequate & $5(100)$ \\
\hline \multirow{2}{*}{ Public telephone } & Inadequate & $8(42.1)$ \\
\hline & Adequate & II (57.9) \\
\hline \multirow{2}{*}{ Floor plan } & Inadequate & $7(36.8)$ \\
\hline & Partially adequate & $12(63.2)$ \\
\hline \multirow{2}{*}{ Bathroom } & Inadequate & $13(68.4)$ \\
\hline & Partially adequate & $6(31.6)$ \\
\hline Food location & Inadequate & $19(100)$ \\
\hline Staircases & Inadequate & $5(100)$ \\
\hline \multirow{2}{*}{ Hallways } & Inadequate & $9(47.4)$ \\
\hline & Adequate & $10(52.6)$ \\
\hline
\end{tabular}

Table Continued.

\begin{tabular}{lll}
\hline Characteristics of the Units & N (\%) \\
\hline General structures & Inadequate & II (57.9) \\
Signage & Partially adequate & $8(42.1)$ \\
& Inadequate & $5(26.3)$ \\
Design & Adequate & $14(73.7)$ \\
Location & Inadequate & II (57.9) \\
Size & Partially adequate & $8(42.1)$ \\
& Inadequate & $19(100)$ \\
Identification & Adequate & $0(0)$ \\
& Inadequate & $8(42.1)$ \\
General signage & Partially adequate & $7(36.8)$ \\
& Adequate & $4(21.1)$ \\
& & \\
General verification & Inadequate & II (57.9) \\
General score & Partially adequate & $8(42.1)$ \\
\hline & & \\
& Inadequate & $10(52.6)$ \\
& Partially adequate & $9(47.4)$ \\
\hline
\end{tabular}

Table 2 Assessment of the differences between the physical structures of FHUs and BHUs in two health districts of a capital city in southern Brazil, 20I I

\begin{tabular}{|c|c|c|c|}
\hline & \multicolumn{2}{|c|}{ Primary Health Care Model } \\
\hline & & FHU & BHU \\
\hline & & n (\%) & n (\%) \\
\hline \multirow{2}{*}{ Transportation } & Inadequate & 7 (63.6\%) & $5(62.5 \%)$ \\
\hline & Partially adequate & $4(36.4 \%)$ & $3(37.5 \%)$ \\
\hline \multirow{2}{*}{ Entrance } & Inadequate & $5(45.5 \%)$ & $5(62.5 \%)$ \\
\hline & Partially adequate & $6(54.5 \%)$ & $3(37.5 \%)$ \\
\hline \multirow{2}{*}{ Parking } & Inadequate & $9(81.8 \%)$ & 7 (87.5\%) \\
\hline & Partially adequate & $2(18.2 \%)$ & $\mathrm{I}(\mathrm{I} 2.5 \%)$ \\
\hline Elevator & Inadequate & I (I00\%) & $4(100 \%)$ \\
\hline \multirow{2}{*}{ Public telephone } & Inadequate & $4(36.4 \%)$ & $4(50 \%)$ \\
\hline & Adequate & $7(63.6 \%)$ & $4(50 \%)$ \\
\hline \multirow{2}{*}{ Floor plan } & Inadequate & $3(27.3 \%)$ & $4(50 \%)$ \\
\hline & Partially adequate & $8(72.7 \%)$ & $4(50 \%)$ \\
\hline \multirow{2}{*}{ Bathroom } & Inadequate & $6(54.5 \%)$ & 7 (87.5\%) \\
\hline & Partially adequate & $5(45.5 \%)$ & $\mathrm{I}(12.5 \%)$ \\
\hline Food location & Inadequate & II (I00\%) & $8(100 \%)$ \\
\hline Staircases & Inadequate & I (I00\%) & $4(100 \%)$ \\
\hline \multirow{2}{*}{ Hallways } & Inadequate & $6(54.5 \%)$ & $3(37.5 \%)$ \\
\hline & Partially adequate & $5(45.5 \%)$ & $5(62.5 \%)$ \\
\hline \multirow{2}{*}{ General structure } & Inadequate & $6(54.5 \%)$ & $5(62.5 \%)$ \\
\hline & Partially adequate & 5 (45.5\%) & $3(37.5 \%)$ \\
\hline
\end{tabular}


Table 3 Assessment of the differences between the signage of FHUs and BHUs in two health districts of a capital city in southern Brazil, 20I I

\begin{tabular}{|c|c|c|c|}
\hline & & \multicolumn{2}{|c|}{ Primary Health Care Model } \\
\hline & & FHU & BHU \\
\hline & & n (\%) & n (\%) \\
\hline \multirow{2}{*}{ Design } & Inadequate & $2(18.2 \%)$ & $3(37.5 \%)$ \\
\hline & Partially adequate & $9(81.8 \%)$ & $5(62.5 \%)$ \\
\hline \multirow{2}{*}{ Location } & Inadequate & $6(54.5 \%)$ & $5(62.5 \%)$ \\
\hline & Adequate & $5(45.5 \%)$ & $3(37.5 \%)$ \\
\hline \multirow[t]{2}{*}{ Size } & Inadequate & II (I00\%) & $8(100 \%)$ \\
\hline & Inadequate & $2(18.2 \%)$ & $6(75 \%)$ \\
\hline \multirow[t]{2}{*}{ Identification } & Partially adequate & $5(45.5 \%)$ & $2(25 \%)$ \\
\hline & Adequate & $4(36.3 \%)$ & 0 \\
\hline \multirow{2}{*}{ Signage } & Inadequate & $5(45.5 \%)$ & $6(75 \%)$ \\
\hline & Partially adequate & $6(54.5 \%)$ & $2(25 \%)$ \\
\hline
\end{tabular}

Table 4 Assessment of the differences between the team characteristics and the operation of FHUs and BHUs in two health districts of a capital city in southern Brazil, 20II

\begin{tabular}{|c|c|c|c|}
\hline & & \multicolumn{2}{|c|}{ Primary Health Care Model } \\
\hline & & FHU & BHU \\
\hline & & n (\%) & n (\%) \\
\hline \multirow{3}{*}{ Number of teams } & I & I (9.2) & $7(87.5)$ \\
\hline & 2 & $8(72.7)$ & I (I2.5) \\
\hline & 3 & $2(18.2)$ & 0 \\
\hline \multirow{2}{*}{ Number of physicians } & 0 to 2 & $9(81.8)$ & 0 \\
\hline & 2 or more & $2(18.2)$ & $8(100)$ \\
\hline \multirow{2}{*}{ Number of nurses } & 1 & I (9.I) & $6(75)$ \\
\hline & 2 or more & $10(90.9)$ & $2(25)$ \\
\hline \multirow{2}{*}{ Number of dentists } & None & $4(36.4)$ & 0 \\
\hline & I or more & $7(63.6)$ & $8(100)$ \\
\hline \multirow{2}{*}{$\begin{array}{l}\text { Number of nursing } \\
\text { technicians }\end{array}$} & 2 or 4 & $8(72.7)$ & 0 \\
\hline & 5 or more & $3(27.3)$ & $8(100)$ \\
\hline \multirow{2}{*}{$\begin{array}{l}\text { Number of oral health } \\
\text { technicians or oral health } \\
\text { assistants }\end{array}$} & None & $5(45.5)$ & $3(37.5)$ \\
\hline & I or more & $6(54.5)$ & $5(62.5)$ \\
\hline \multirow{2}{*}{$\begin{array}{l}\text { Number of community } \\
\text { health agents }\end{array}$} & None & $4(36.4)$ & $8(100)$ \\
\hline & 4 or more & $7(63.6)$ & 0 \\
\hline \multirow{2}{*}{$\begin{array}{l}\text { Training for elderly health } \\
\text { care }\end{array}$} & 0 & $2(18.2)$ & $3(37.5)$ \\
\hline & I or more & $9(81.8)$ & $5(62.5)$ \\
\hline \multirow{2}{*}{ Telephone scheduling } & Yes & $10(90.9)$ & $7(87.5)$ \\
\hline & No & I (9.1) & I (12.5) \\
\hline \multirow{2}{*}{ Elderly group } & Yes & $10(90.9)$ & $4(50)$ \\
\hline & No & I (9.I) & $4(50)$ \\
\hline \multirow{2}{*}{ Home visits } & Yes & II (100) & 7 (87.5) \\
\hline & No & 0 & I (12.5) \\
\hline \multirow{2}{*}{ Has a dental office } & Yes & $7(63.6)$ & $6(75)$ \\
\hline & No & $4(36.4)$ & $2(25)$ \\
\hline \multirow{2}{*}{$\begin{array}{l}\text { Office } w / \text { wheelchair } \\
\text { accessibility }\end{array}$} & Yes & $5(7 I .4)$ & $5(83.3)$ \\
\hline & No & $2(28.6)$ & I (I6.7) \\
\hline
\end{tabular}

\section{Discussion}

This study is innovative for assessing the adequacy of the physical structures of health units for the needs of the elderly, because the use of the document "Primary Health Care-Age-Friendly Centres Toolkit"7 allowed analyzing the accessibility of the elderly population to the health services responsible for their care. Additionally, the study allowed showing some characteristics of the primary health care team considered essential to the comprehensive care of elderly users. Currently, the ageing of the population is part of the global reality in most societies and it is estimated that by 2050 there will be approximately 2 billion elderly people living in the world. ${ }^{10}$ Therefore, government strategies are required to include this portion of the population and provide an independent and healthy ageing process for all elderly people. Among the main global strategies, the World Health Organization (WHO) launched in Spain, in 2002, the project "Active Ageing", a health policy aiming to optimize the possibilities for health promotion, safety, and elderly participation, seeking a better quality of life throughout their lives. ${ }^{11}$ In 2004, the document "Toward Primary Health Care - Age-Friendly" was published, aiming to adapt public policies and managers for the adequacy of primary health care services, ensuring accessibility and adequate care for the elderly population, working in specific areas for this purpose, such as information, education, communication, training, health care management systems, and adequacy of physical structures. ${ }^{12}$ At first, the observations obtained in this study show major differences between the recommendations of the WHO for the adequacy of physical structures and signage and the actual situation of the health units assessed. These findings indicate major limitations in the accessibility of the elderly to health services, suggesting that the barriers for accessing the health units do not correspond to an effective and comprehensive care. ${ }^{13,14} \mathrm{~A}$ recent study performed in the state of Paraíba, Brazil, observed a reduced social insertion due to limited mobility in several types of spaces, and this was the main barrier for the social interaction among people with disabilities. Most part of the sample of said study, consisting of individuals registered at Family Health Units, included elderly people. ${ }^{15}$ In the Brazilian scope, one of the first movements observed toward the creation of specific public policies for the elderly was in 1999, with decree 1.395, which addressed the need for adequacy of the Unified Public Health Care System to handle the epidemiological transition and the high costs that elderly health may represent to the Brazilian health system. ${ }^{16}$ Later, in 2003 and shortly after, in 2006, the Statute for the Elderly and the Pact for Life were established, and these highlighted the assurance of universal and equal access to an articulated and continuous set of actions and services. ${ }^{17,18}$ When extending the outlook on accessibility, the Brazilian population with disabilities should be noted. In 1994, the Brazilian Standard 9050 was created by the Brazilian Association of Technical Standards, ${ }^{19}$ reporting that the promotion of accessibility in the constructed environment means to promote mobility conditions with autonomy and safety to users, eliminating the architectural and urban barriers in the cities, and the means of transportation and communication. ${ }^{20}$ However, when observing the manual of accessibility ${ }^{21}$ and signage ${ }^{22}$ offered by the Brazilian System of Construction Monitoring (SISMOB), there is little attention to the needs and adequacies suggested by the $\mathrm{WHO}^{11,12,}$ also observed in this study. The architectural barriers consist of every and any structure capable of challenging or preventing the exercise of an individual in moving freely and easily. These barriers are the presence of staircases, high stairs, absence of ramps and support bars, among others, especially challenging people with temporary limitations, people with disabilities, and the elderly4. Regarding the spaces designed for health care, the reality observed in this study 
corresponds to the comprehensive health care and the active and independent ageing, therefore with the pressing need to unblock and prevent the existence of any type of barrier. This was not confirmed by our findings as it has been confirmed in other studies performed in institutions willing to provide care for the elderly. ${ }^{23}$ In a study performed by Vasconcelos \& Pagliuca. ${ }^{24}$ the physical structures of health units in a medium-sized city were assessed according to the proposal by the Brazilian Standard 9050/94. The results indicate the lack of adequacy of environments for an easy accessibility of users with disabilities, which is also reflected in the present study, but targeted to the elderly population, ${ }^{7-24}$ considering that the units were mostly inadequate in matters of structure. Such findings also found similar relation to the findings by Lima et al. ${ }^{25}$ when listening to elderly people from the city of São Paulo, Brazil, who reported the physical structure of the health units they use as moderate, poor, or very poor, suggesting the attention of the health team and managers for this issue. Hearing and visual impairments are common diseases among the elderly population. Several evidences affirm that the prevalence of these diseases increases according to the age of individuals. ${ }^{26-29}$ The epidemiological reality places the importance of adequate signage in health units and the identification of professionals. The present study showed that most of the units were inadequate for these parameters, with better results for the Family Health Strategy units. Added to the physical and motor impairments, the search and wait for services may become obstacles when they are not adequate to the particularities of the elderly. In 2010, the city hall of Porto Alegre, RS, Brazil, approved the Municipal Law 10.819, which establishes the possibility of telephone scheduling for elderly patients and people with disabilities who are already registered at the health units of the city. ${ }^{30}$ The action complements the objectives of the Basic Health Care Book 19 and the proposals of the Primary Health Care - Age-Friendly Toolkit for qualifying the answers and the primary health care of the elderly. ${ }^{7-18}$ In the checklist used in this study, telephone scheduling was offered in a great portion of the health units, except for one Family Health Unit and one Basic Health Unit. Therefore, the law extended the availability of this service in the city studied, but the compliance of the legislation for all health units is pending. After establishing the intention of the health actions targeted to the particularities of the elderly, it is also required that health professionals can admit, identify, and care for this community. The Statute of the Elderly, approved in 2003, determines that the health institutions should meet the minimum criteria for serving the needs of the elderly, promoting professional training and qualification, as well as guiding caregivers, family members, and coexistence groups. ${ }^{17}$ The observation hereby performed, aiming to identify the qualification of health team professionals for the care of the elderly, showed that almost all FHUs had one or more trained professionals, while this rate was lower in BHUs. This fact was repeated for the presence of elderly groups, which suggests that FHUs are more qualified to offer care services and promote health for this line of care that is complex and rather present in health care services, at least in this context. Rebouças et al. ${ }^{31}$ affirmed that ageing in current times is the cause and, at the same time, the consequence of social changes. Therefore, it is required to establish new lifestyles, values, and identities that are socially acknowledged, in order to ensure the rights of population groupings with daily needs that demand adequate answers. Lastly, although this study has limitations, such as its cross-sectional design and the sampling of a rather limited territory of a single city, we believe that it might serve as basis for further studies and to elucidate adequacies required, especially when the primary health care in Brazil takes on the leading role by means of several affirmative public policies and when there is a public policy proposing to assess and qualify health care services.

\section{Final considerations}

After verifying the health units, both FHUs and BHUs, we found that their physical structures do not reach the adequacy standards from the guidelines proposed by the World Health Organization. As for the detailing of analysis and separating the results from FHUs and BHUs, it was clear that FHUs presented better results for both physical structure and signage issues, suggesting that they were more adequate to provide care services to the elderly population; however, the overall results are still far from ideal. Lastly, when observing the primary health care teams and work processes of the services assessed, again, the results indicate that FHUs are more adequate to provide qualified care services to the elderly. These results seem to indicate that family health may be the most adequate model for the care for this age group of the population, considering the importance of workers and the processes they apply to health care, which is effective for meeting and relating to the territory and to the actual needs of the user population, promoting the comprehensive, interdisciplinary, and continuous care desired and complying with the comprehensive and integrated care aimed for the health care policy of the elderly person..$^{23}$ Acknowledging and legitimizing old age has been a point for consideration in different societies. Consequently, the advances need to materialize for all citizens. The challenge hereby raised regard to the populations with the greatest social needs, so to ensure the place to be occupied by the new elderly person in the Brazilian society.

\section{Funding}

None.

\section{Acknowledgments}

This project was approved by the Research and Ethics Committee of the School of Dentistry of the Federal University of Rio Grande do Sul (UFRGS), Brazil, on June 18, 2009, record \#05/09, and process \#15297. The study was funded with resource granted by the FAPERGS, publication 002/2009 - PPSUS 2008/2009.

\section{Conflicts of interest}

None.

\section{References}

1. Unglert CVS, Rosenburg CP, Junqueira CB. Acesso aos serviços de saúde: uma abordagem de geografia em saúde pública. Rev Saúde Pública. 1987;21(5):439-446.

2. Johnes RGS, Micheline NAG, André Luiz DB. Direito à saúde: revisão Integrativa da literatura sobre o acesso de idosos aos serviços de Saúde. C\&D-Revista Eletrônica da Fainor. 2012;5(1): 25-42.

3. Prata PR. The epidemiologic transition in Brazil. Cad Saúde Pública. 1992;8(2):168-175.

4. Siqueira FCV, Facchini LA, Silveira DS, et al. Barreiras arquitetônicas a idosos e portadores de deficiência física: um estudo epidemiológico da estrutura física das unidades básicas de saúde em sete estados do Brasil. Ciênc saúde coletiva. 2009;14(1): 39-44.

5. Eriksen MD, Greenhalgh-Stanley N, Engelhardt GV. Home safety, accessibility, and elderly health: Evidence from falls. Journal of Urban Economics. 2015;87(C): 14-24. 
6. Ribeiro Adalgisa Peixoto, Souza Edinilsa Ramos de, Atie Soraya, et al. The influence of falls on the quality of life of the aged. Ciênc saúde coletiva. 2008;13(4):1265-1273.

7. World Health Organization. Age-Friendly Primary Health Care Centres Toolkit. Geneva, Switzerland. 2008; p. 1-117.

8. Ministério Da Saúde; Secretaria De Atenção À Saúde; Departamento De Atenção Básica. Envelhecimento e saúde da pessoa idosa, Brazil. 2007.

9. IBGE. Instituto Brasileiro De Geografia E Estatística. Censo Demográfico, Brazil. 2010

10. Ministério da Saúde; Envelhecimento e saúde da pessoa idosa, Secretaria de Atenção à Saúde, Departamento de Atenção Básica, Brazil. 2006.

11. World Health Organization. Active ageing, a policy framework. Geneva, Switzerland, 2002; p. 59.

12. World Health Organization. Towards age-friendly primary health care Geneva, Switzerland, 2004; p. 40.

13. Ministério da Saúde. Manual de estrutura física das unidades básicas de saúde: saúde da família. Brasília: Ministério da Saúde, Brazil. 2006.

14. Ministério da Saúde. Manual de estrutura física das unidades básicas de saúde: saúde da família, Brazil. 2008.

15. Holanda CMA, Andrade FLJP, Bezerra MA, et al. Redes de apoio pessoas com deficiência física: inserção social e acesso aos serviços de saúde. Ciênc. saúde coletiva. 2015;20(1):175-184.

16. Ministério da Saúde. Portaria no 1.395/GM, Brazil. 1999.

17. Estatuto do idoso: lei federal no 10.741, de 01 de outubro de 2003. DF: Secretaria Especial dos Direitos Humanos, Brazil. 2003.

18. Ministério da Saúde. Diretrizes operacionais: pactos pela vida em defesa do SUS e de gestão. 2nd ed, Ministério da Saúde, Brazil, 2006; p. 1-75.

19. Associação Brasileira De Normas Técnicas. NBR 9050.1994.
20. Acessibilidade de pessoas portadoras de deficiências a edificação espaço mobiliário e equipamentos urbanos. ABNT NBR 9050, Rio de Janeiro, Brazil. 2004.

21. Ministério da Saúde. Acessibilidade em Unidades Básicas de Saúde. Ministério da Saúde, Brazil. 2015. p. 22.

22. Ministério da Saúde. Manual de identidade visual: saúde mais perto de você, Brazil, 2012. p. 30.

23. Lima MRS, Raimunda MS, Maria EO. Avaliação da acessibilidade de uma instituição de longa permanência para idosos no município de Teresina-PI. Revista Interdisciplinar. 2014;7(1):34-40.

24. Vasconcelos LR, Pagliuca LMF. Mapeamento da acessibilidade do portador de limitação física a serviços básicos de saúde. Escola Anna Nery Revista de Enfermagem. 2006;10(3):494-500.

25. Lima TJV de, Arcieri RM, Garbin CAS, et al. Humanização na atenção básica de saúde na percepção de idosos. Saude soc. 2014;23(1):265-276.

26. Fook L, Morgan R. Hearing impairment in older people: a review. Postgraduate Medical Journal. 2000;76(899):537-541.

27. Picavet HSJ, Hoeymans N. Physical disability in the Netherlands: prevalence risk groups and time trends. Public Health. 2002; 116(4):231237.

28. Dunzhu S, Wang FS, Courtright $\mathrm{P}$, et al. Blindness and eye diseases in Tibet: findings from a randomised, population based survey. $\mathrm{Br} J$ Ophthalmol. 2003;87(12):1443-1448.

29. Melese M, Alemayehu W, Bayu S, et al. Low vision and blindness in adults in Gurage Zone, central Ethiopia. The British Journal of Ophthalmology. 2003;87(6):677-680.

30. Prefeitura Municipal de Porto Alegre. Lei $N^{o}$ 10.819. Prefeitura Porto Alegre. Janeiro, Brazil. 2010 